\title{
A service evaluation of the impact of adoption of JBDS guidelines for the management of glucose during labour and birth in women with diabetes
}

\author{
UMESH DASHORA, ${ }^{1}$ SUHAIL AHMED, ${ }^{1}$ IRENE BOSSMAN, ${ }^{1} \mathrm{KO}$ KO AUNG, ${ }^{2}$ ERWIN CASTRO, ${ }^{1}$ \\ PARIASAMY SATHISKUMAR ${ }^{1}$
}

\begin{abstract}
Aims: The aim of this retrospective observational study was to report on the impact of adopting the Joint British Diabetes Society for Inpatients (JBDS-IP) guidelines on the achievement of targets recommended by the National Institute for Health and Care Excellence (NICE) and the maternal and neonatal outcomes.

Methods: We analysed case records of pregnant women with diabetes who delivered in the period between November 2017 and October 2018 from our data base 'Euroking' (Wellbeing Software Ltd, Mansfield). Data were collected in relation to the availability of a dedicated prescription chart in the notes, capillary blood glucose (CBG) monitoring, use of variable rate intravenous insulin infusion (VRIII), maintenance of CBG targets within 4.0-7.0 $\mathrm{mmol} / \mathrm{L}$, maternal hypoglycaemia during labour when on VRIII and neonatal hypoglycaemia.

Results: Sixty women with diabetes in our database delivered during this period. Thirty-six $(60 \%)$ were monitored with hourly CBG monitoring and $30(50 \%)$ achieved CBG levels within the NICE recommended target range. Only five women $(8.3 \%)$ were started on VRIII. There was no maternal hypoglycaemia in the VRIII group. One baby $(1.7 \%)$ developed mild neonatal hypoglycaemia.

Conclusion: Adoption of JBDS guidelines contributed to $60 \%$ of women with diabetes receiving complete CBG monitoring, of whom $70 \%$ achieved the NICE recommended target of 4.0-7.0 mmol/L during labour and birth. Repeat CBG measurements before starting VRIII, strict adherence to clear JBDS guidelines and protocols, daily review by the diabetes
\end{abstract}

Diabetes and Endocrine Centre, Conquest Hospital, Hastings, UK

Southend University Hospital, UK

Address for correspondence: Dr Umesh Dashora

Consultant, Diabetes and Endocrinology, Conquest Hospital, The Ridge,

St Leonards on Sea TN7 7RD, UK

Tel: 01424755255

E-mail: u.dashora@nhs.net

https://doi.org/10.15277/bjd.2021.287 team during the working week and appropriate use of VRIII was associated with good maternal and neonatal outcomes. Br J Diabetes 2021;21:67-75

Key words: JBDS, NICE, targets, diabetes, delivery, neonatal, hypoglycaemia, outcome

\section{Introduction}

Infants born to mothers with diabetes have higher morbidity, ${ }^{1}$ including the risk of neonatal hypoglycaemia, and many of these adverse outcome are unaffected by pre-pregnancy care. ${ }^{2}$ Neonatal hypoglycaemia is thought to be secondary to beta cell hyperplasia in the infant pancreas following maternal hyperglycaemia in pregnancy. ${ }^{3-6}$ It is not uncommon. ${ }^{7}$ It may have significant consequences on the neural development of the child, which may become apparent at a later age ${ }^{8}$ and needs to be prevented, identified and promptly treated. It has been hypothesised that the last 18 hours in utero is important to prevent neonatal complications, even in women with good glycaemic control during pregnancy. ${ }^{9}$

The National Institute for Health and Care Excellence (NICE) recommends maintaining maternal blood glucose between 4.0 and $7.0 \mathrm{mmol} / \mathrm{L}$ during labour and birth to reduce neonatal hypoglycaemia. ${ }^{1}$ The use of a combined insulin and glucose infusion to maintain maternal blood glucose in the target range has been suggested. ${ }^{1}$

In contrast, some studies have questioned the definition of neonatal hypoglycaemia and its relationship to maternal hyperglycemia. ${ }^{10}$ They also raised concerns that maintaining tight glycaemic control in the range of $4.0-7.0 \mathrm{mmol} / \mathrm{L}$ may increase maternal hypoglycaemia and resource burden without any clear reduction in neonatal hypoglycaemia. ${ }^{11-13}$ However, the relaxed targets in some of these studies $(3.3-6.7 \mathrm{mmol} / \mathrm{L})$ are tighter than NICE recommended targets $(4.0-7.0 \mathrm{mmol} / \mathrm{L}) .^{14}$ The evidence of a safer relaxed target therefore is not clear.

We adopted Joint British Diabetes Society (JBDS) guidelines for diabetes control during labour and birth in November 2017. As per the guidelines, we performed capillary blood glucose (CBG) monitoring hourly from the onset of labour in all women with any type of diabetes. Variable rate intravenous insulin infusion (VRIII) 
was started in women only if two consecutive CBG levels were $>7.0 \mathrm{mmol} / \mathrm{L}$ or if the woman had type 1 diabetes. The VRIII scale was adjusted to keep CBG between 4.0 and $7.0 \mathrm{mmol} / \mathrm{L}$, as recommended by NICE. ${ }^{15,16}$

The current retrospective observational cohort study was undertaken to investigate the adherence, feasibility and effectiveness of our new protocol based on JBDS guidelines in reaching NICE recommended targets and the resultant impact on neonatal hypoglycaemia. We also wanted to see if VRIII use increased the risk of maternal hypoglycaemia. We had a high incidence of neonatal hypoglycaemia and some maternal hypoglycaemia on VRIII in our previous study ${ }^{17}$ and we were keen to see the impact of the revised approach on these two outcomes.

\section{Methods}

A list of mothers with diagnosed diabetes mellitus (gestational, type 1 and type 2) who delivered during the period from November 2017 to October 2018 was compiled from the obstetric Euroking database (Wellbeing Software Ltd, Mansfield, UK).

Case records were analysed for the type of diabetes, insulin use and if there were appropriate plans for labour with VRIII and CBG forms in their files. The JBDS guidelines-driven plan that we started using in September 2017 is shown in Figure 1, and was slightly different from the local protocol that we used last time. Basal insulin when used is continued during labour, and meal time insulin is continued as long as CBG levels are within the target range. Once the patient is in established labour and is either known to have type 1 diabetes or the CBG is $>7.0 \mathrm{mmol} / \mathrm{L}$ on two consecutive occasions (rather than a single reading as in the previous protocol) or is not reliably eating and drinking, VRIII is started. Once VRIII is started, basal insulin is continued and meal time insulin is withheld.

The records were also analysed for CBG levels during labour, appropriate use of VRIII, type of delivery, maternal hypoglycaemia during VRIII and the incidence of neonatal hypogly- caemia. Fisher's exact test was used to determine statistical significance.

CBG monitoring was considered incomplete if any readings were missing from the chart, except if the delivery was within half an hour of admission. Maternal hypoglycaemia and neonatal hypoglycaemia were defined as a level below $4.0 \mathrm{mmol} / \mathrm{L}$ and $2.6 \mathrm{mmol} / \mathrm{L}$, respectively, for the purpose of this study.

\section{Results}

We identified 60 women with diabetes from the database who delivered between November 2017 and October 2018. Fiftyseven women had gestational diabetes, two had type 2 diabetes and one had type 1 diabetes (see Tables 1 and 2). The treatment included diet alone $(n=18)$, oral medications $(n=17)$, insulin $(n=11)$ or a combination of insulin with oral drugs $(n=14)$. Fiftyfive were Caucasians, three were of Indian extraction and two were of Chinese extraction. Thirty-six women had no obstetric complications but six had macrosomia and 15 had polyhydramnios. Twenty-seven women had a normal vaginal delivery but 14 had elective caesarean section (CS), five had an emergency CS and 14 needed forceps delivery. One delivery was pre-term. Fiftyeight women (97\%) had an appropriate prescription plan and $54(90 \%)$ had a CBG monitoring chart in their notes before admission for delivery. All women were reviewed by the diabetes team daily during the working week after admission.

\section{CBG monitoring}

Forty-two women (70\%) received some CBG monitoring as per protocol. In 18 cases (30\%) we could not find any documentation of CBG records. Of those monitored $(n=42), 36(86 \%)$ had complete hourly CBG monitoring and six (14\%) had at least one reading missed. In two cases the CBG was considered satisfactory and therefore classed as complete even when there was no CBG record due to quick deliveries within half an hour of hospital admission. Thirty (50\%) women remained in the NICE

Table 1 Comparison of our studies on glycaemic control during labour and birth with $n$ (rounded up \%) if applicable: baseline characteristics

\begin{tabular}{|c|c|c|}
\hline Period of study & July 2014 to June 2015 & Nov 2017 to October 2018 \\
\hline $\begin{array}{l}\text { Women who delivered over the period as per Euroking } \\
\text { database (actual number higher) }\end{array}$ & $51(100)$ & $60(100)$ \\
\hline Trigger in the protocol for starting VRIII in labour & $\begin{array}{l}\text { Hourly CBG during labour and VRIII } \\
\text { started if one reading }>7.0 \mathrm{mmol} / \mathrm{L}\end{array}$ & $\begin{array}{l}\text { Hourly CBG during labour and start VRIII } \\
\text { if } 2 \text { consecutive readings }>7.0 \mathrm{mmol} / \mathrm{L}\end{array}$ \\
\hline Treated with insulin & $25(50)$ & $11(18)$ \\
\hline Treated with insulin + oral drugs & $10(20)$ & $14(23)$ \\
\hline Macrosomia & $15(29)$ & $6(10)$ \\
\hline Polyhydramnios & $6(12)$ & $15(25)$ \\
\hline
\end{tabular}


Figure 1. Prescription chart based on JBDS guidance and used in our Trust

\section{East Sussex Healthcare \\ NHS Trust \\ Intravenous Insulin Prescription and Fluid Protocol PREGNANCY AND LABOUR ONLY \\ For use during pregnancy and labour for ALL patients receiving Variable Rate Intravenous Insulin Infusion (VRIII) NEVER use an IV syringe to draw up insulin \\ ALWAYS draw up insulin using an insulin syringe ALWAYS continue subcutaneous basal insulin \\ WHS}

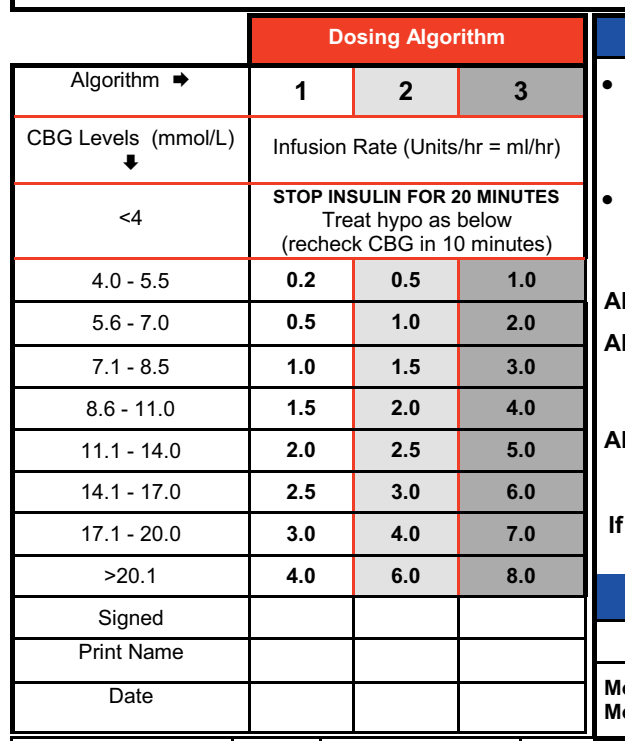

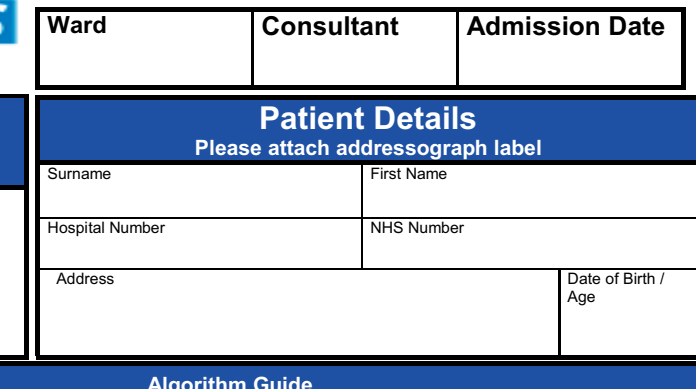

\section{Algorithm Guide}

ALL women with diabetes should have Capillary Blood Glucose (CBG) testing hourly in established labour or at least once on admission for induction of labour or elective C-Section

Start VRIII and Fluids if two consecutive CBGs > target (see below) or at the start of established labour if the woman has type 1 diabetes

Algorithm 1 Most women will start here

Algorithm 2 Use this algorithm for women who are likely to require more insulin (On steroids, on $>80$ units of insulin during pregnancy) or those not achieving target on algorithm 1

Algorithm 3 Use this for women who are not achieving target on algorithm 2 No patient starts here without diabetes or medical review If the woman is not achieving targets with these algorithms, contact the diabetes team (out of hours: Medical SpR on call)

\section{Target CBG Levels 4-7 mmol/}

Check CBG every hour whilst on IV insulin

Move Up if the CBG is $>7 \mathrm{mmol} / \mathrm{l}$ and has not reduced in 1 hour Move Down (when using higher algorithms) if CBG is $<4 \mathrm{mmol} / \mathrm{L}$

\begin{tabular}{|c|c|c|c|}
\hline $\begin{array}{c}\text { Insulin (approved } \\
\text { name) }\end{array}$ & Dose & Volume & Route \\
\hline Human Actrapid@ & $\begin{array}{c}\mathbf{5 0} \\
\text { UNITS }\end{array}$ & $\begin{array}{c}\text { Made up to } 50 \mathrm{ml} \\
\text { with SODIUM } \\
\text { CHLORIDE 0.9\% } \\
\text { (1 UNIT per } \mathrm{ml})\end{array}$ & IV \\
\hline
\end{tabular}

Move Down (when using higher algorithms) if $C B G$ is $<4 \mathrm{mmol} / \mathrm{L}$

\section{SYRINGE PREPARATION}

\begin{tabular}{|l|l|l|l|}
\hline $\begin{array}{c}\text { Prepared \& } \\
\text { administered by }\end{array}$ & Date & $\begin{array}{c}\text { Time start- } \\
\text { ed }\end{array}$ & Time stopped \\
\hline & & & \\
\hline & & & \\
\hline & & & \\
\hline
\end{tabular}

INTRAVENOUS SUBSTRATE FLUID

\begin{tabular}{|c|c|c|c|c|}
\hline Date & Intravenous Fluid and Rate & Alternative Rate & $\begin{array}{c}\text { Prescriber's } \\
\text { Signature }\end{array}$ & $\begin{array}{c}\text { Nurse's } \\
\text { Signature }\end{array}$ \\
\hline & $500 \mathrm{mls} 0.9 \% \mathrm{NaCl}+5 \%$ Dextrose with $10 \mathrm{mmol} \mathrm{KCl}(0.15 \%)$ to run at $50 \mathrm{mls} / \mathrm{hr}$ & $\mathrm{mls} / \mathrm{hr}$ & & \\
\hline & $500 \mathrm{mls} 0.9 \% \mathrm{NaCl}+5 \%$ Dextrose with $10 \mathrm{mmol} \mathrm{KCl}(0.15 \%)$ to run at $50 \mathrm{mls} / \mathrm{hr}$ & $\mathrm{mls} / \mathrm{hr}$ & & \\
\hline
\end{tabular}

\section{HYPOGLYCAEMIA MANAGEMENT}

\begin{tabular}{|l|l|c|l|l|l|l|l|}
\hline Date & Preparation & Volume & Route & Duration & Prescriber's Signature & Nurse's Signature & Time given \\
\hline & $20 \%$ Dextrose & $100 \mathrm{mls}$ & IV & $15 \mathrm{mins}$ & & & \\
\hline & $20 \%$ Dextrose & $100 \mathrm{mls}$ & IV & $15 \mathrm{mins}$ & & & \\
\hline
\end{tabular}

C AP I L LARY B L O O D G L U C OSE M O N I T OR I N G (hourly after starting infusion)

\begin{tabular}{|l|l|l|l|l|l|l|l|l|l|l|l|l|}
\hline Date: & $01: 00$ & $02: 00$ & $03: 00$ & $04: 00$ & $05: 00$ & $06: 00$ & $07: 00$ & $08: 00$ & $09: 00$ & $10: 00$ & $11: 00$ & $12: 00$ \\
\hline CBG & & & & & & & & & & & & \\
\hline Insulin Rate & & & & & & & & & & & & \\
\hline Blood Ketones & & & & & & & & & & & & \\
\hline Initials & & & & & & & & & & & & \\
\hline Date: & $13: 00$ & $14: 00$ & $15: 00$ & $16: 00$ & $17: 00$ & $18: 00$ & $19: 00$ & $20: 00$ & $21: 00$ & $22: 00$ & $23: 00$ & $24: 00$ \\
\hline CBG & & & & & & & & & & & & \\
\hline Insulin Rate & & & & & & & & & & & & \\
\hline Blood Ketones & & & & & & & & & & & & \\
\hline Initials & & & & & & & & & & & & \\
\hline
\end{tabular}

GESTATIONAL DIABETES:

STOP VRIII and IV Substrate

Fluid regime once placenta is delivered

TYPE 1 DM AND INSULIN TREATED TYPE 2 DM:

Reduce the rate of VRIII by

HALF once placenta is delivered

Contact diabetes team to review ongoing insulin requirements

Maintain IV infusion for 30 minutes after re-starting original insulin regime-IV insulin has a 5 minute half life 
Figure 1. Prescription chart based on JBDS guidance and used in our Trust (continued)

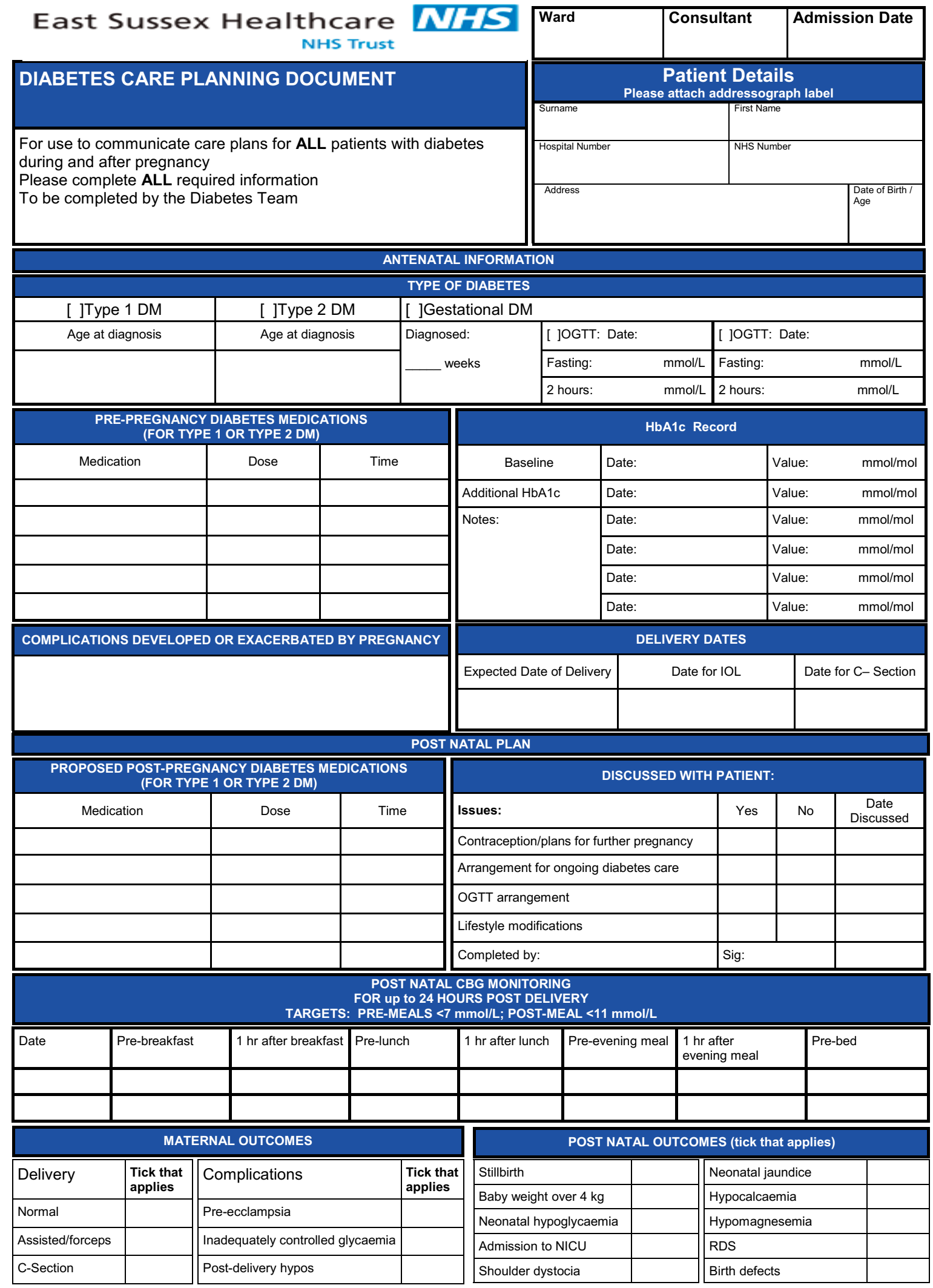


Table 2 Comparison of our studies on glycaemic control during labour and birth with $\mathrm{n}$ (rounded up \% of the cohort or the group) if applicable: observations/outcomes

\begin{tabular}{|c|c|c|}
\hline Period of study (n) & July 2014 to June $2015(n=51)$ & Nov 2017 to October $2018(n=60)$ \\
\hline Daily review by diabetes team during working week & $39(76)$ & $60(100)$ \\
\hline Some CBG monitoring & $27(53)$ & $42(70)$ \\
\hline Women with CBG in target out of women monitored & $7(26)$ & $30(71)$ \\
\hline Elective CS & $17(33)$ & $14(23)$ \\
\hline Delivery by modes other than elective CS & $34(67)$ & $46(77)$ \\
\hline $\begin{array}{l}\text { Women delivered by modes other than elective CS who } \\
\text { received complete hourly CBG monitoring }\end{array}$ & $18(53)$ & $\begin{array}{l}33(72) p<0.0013 \text { vs women } \\
\text { delivered by elective CS }\end{array}$ \\
\hline Women who were considered eligible for VRIII & $14(27)$ & $5(8)$ \\
\hline VRIII missed inappropriately & $5(10)$ & $0(0)$ \\
\hline VRIII effective in controlling CBG satisfactorily & $2(22)$ & $5(100)$ \\
\hline $\begin{array}{l}\text { Women on VRIII who delivered babies with neonatal } \\
\text { hypoglycaemia }\end{array}$ & $4(44)$ & $0(0)$ \\
\hline $\begin{array}{l}\text { Neonatal hypoglycaemia in babies born to women } \\
\text { who inappropriately missed VRIII }\end{array}$ & $4(80)$ & $0(0)$ \\
\hline $\begin{array}{l}\text { Women on VRIII who developed maternal } \\
\text { hypoglycaemia }\end{array}$ & $2(22)$ & $0(0)$ \\
\hline Women with GDM & $41(80)$ & $57(95)$ \\
\hline Women with GDM who received VRIII & $6(15)$ & $4(7)$ \\
\hline Women with type 1 diabetes & $5(10)$ & $1(2)$ \\
\hline
\end{tabular}

recommended target range of $4.0-7.0 \mathrm{mmol} / \mathrm{L}$ and $12(20 \%)$ could not be maintained within the target range. Of the 30 women whose CBG remained in the target range, nine were on diet alone whereas five needed addition of metformin, seven were on insulin alone and nine needed metformin in combination with insulin. The mean (SD) basal insulin dose was 7 (9.8) units with a range of 0-38 units and the mean (SD) bolus insulin dose was 3 (5.7) units with a range of $0-20$ units. The highest dose of insulin in this group was 45 units. Poor monitoring was more common in women who had elective CS compared with delivery by other means ( $p=0.0013$, significant at 0.05 level by Fisher's exact test). Six women who delivered normally, eight who had elective CS and four who had forceps delivery had no records of CBG monitoring and all delivered within 2 hours of presentation. There was no relationship between the completeness of CBG monitoring and whether or not the women were treated with insulin.
Women who received or missed VRIII during delivery

With the adoption of JBDS guidance, only five women (8.3\%) were started on VRIII. Four women had gestational diabetes and one had type 1 diabetes. Four women had two consecutive CBG readings of $>7.0 \mathrm{mmol} / \mathrm{L}$ (range $9.0-11.0 \mathrm{mmol} / \mathrm{L}$ ) and received VRIII appropriately. In one woman VRIII was started at a CBG level of $5.1 \mathrm{mmol} / \mathrm{L}$ as steroids were given for prematurity (as per JBDS protocol). VRIII was able to maintain CBG levels satisfactorily - that is, either within target range or with improving levels - in all cases except if delivery occurred in such a short period that a change in VRIII scale was neither possible nor needed. There was no incidence of neonatal hypoglycaemia in the babies born to any of these women. Two women missed VRIII after two consecutive CBG readings of $>7.0 \mathrm{mmol} / \mathrm{L}$ due to quick deliveries within an hour and the babies did not have neonatal hypoglycaemia. Three women had only one CBG read- 
ing $>7.0 \mathrm{mmol} / \mathrm{L}$ and would have been put on VRIII according to the old guidance but did not get VRIII according to the JBDS protocol. The babies of these women did not have neonatal hypoglycaemia. No woman on VRIII developed maternal hypoglycaemia.

Woman who delivered baby with neonatal hypoglycaemia Only one baby (1.7\%) deveoped mild neonatal hypoglycaemia with a CBG level of $2.3 \mathrm{mmol} / \mathrm{L}$ born to a 29 -year-old mother, gravida 1, Caucasian, with gestational diabetes who had no complications during pregnancy and was on insulin. The CBG improved with breast feeding. There was no record of $\mathrm{HbA}_{1 \mathrm{c}}$. She had elective CS. She did not have her CBG checked before or during section and no VRIII was started. One baby out of 60 had no CBG record.

\section{Women who developed maternal hypoglycaemia during labour}

Although no woman developed hypoglycaemia on VRIII, 12 women (20\%) had 22 episodes of minor hypoglycaemia (corrected without the need of third party assistance) picked up on hourly CBG monitoring. One mother had a CBG of $2.4 \mathrm{mmol} / \mathrm{L}$ 30 minutes after delivery and another one had a CBG of 3.7 $\mathrm{mmol} / \mathrm{L}$ after $\mathrm{CS}$. Three of these women were only diet treated, five were on metformin, four were receiving insuin treatment and two were on metfomin and insuin. Many of these episodes were asymptomatic, although as it was a retropective review of case notes an accurate record of symptoms was not available. There were four readings $<4.0 \mathrm{mmol} / \mathrm{L}$ in one woman on CBG monitoring during labour at 2, 3, 4 and 5 hours after being in established labour. Two other women each had three readings $<4 \mathrm{mmol} / \mathrm{L}$. All except one of the CBG readings in the cohort were beween 3.0 and $4.0 \mathrm{mmol} / \mathrm{L}$. All episodes were easily treated as per hospital protocol.

\section{Discussion}

This study has shown that, with the adoption of the JBDS guidelines for the management of diabetes during labour and birth, we had a high proportion of women in established labour with complete CBG monitoring and achievement of NICE recommended target CBG levels, very few women needing VRIII and a very low incidence of neonatal hypoglycaemia.

\section{CBG monitoring}

It is difficult for midwives to maintain hourly CBG monitoring until the end of labour. NICE has suggested a staffing level of one midwife for each mother in labour; ${ }^{18}$ however, this can be difficult to achieve in some hospitals. In our hospital it is not uncommon for midwives to care for two women at a time, at least immediately after admission. Some of the CBG measurements might have been misplaced and therefore recorded as not done. In our study, 36 (60\%) women received complete CBG monitoring from the onset of labour to birth.

A significant number of patients had quick deliveries due to either elective CS (8 women) or quick deliveries within 2 hours of presentation to hospital (10 women). We could not find any records of CBG monitoring in these 18 women. This group can explain the monitoring gap we picked up in our study. As the CS patients are not in labour, the hourly monitoring is delayed until the patient is ready to be taken to theatre. Similar findings were noted in our earlier study when women who delivered by CS did not have CBG monitored. ${ }^{17}$ Early start of monitoring may pick up glucose abnormalities in some of these patients. Subsequent early and appropriate action has the potential to maintain patients within the NICE recommended target. This in turn has the potential to reduce neonatal hypoglycaemia and other complications. The only baby who had neonatal hypoglycaemia in the current study was delivered by elective CS, and we could not find any evidence of CBG monitored in the woman.

Of those women where any monitoring was available, 30 (71\%) had their CBG within the target range of $4.0-7.0 \mathrm{mmol} / \mathrm{L}$ compared with only seven $(26 \%)$ in our previous study. This might be partly due to the new protocol, diabetes team review and the education that accompanied it.

\section{Use of VRIII}

In the current study only five women (8.3\%) needed VRIII compared with nine (17.6\%) in our previous study. ${ }^{17}$ The JBDS guidelines suggest two consecutive CBG levels to be $>7.0 \mathrm{mmol} / \mathrm{L}$ to trigger VRIII. A similar watchful wait approach has been described in some other studies. ${ }^{19}$ This approach helped avoid VRIII in five women, all of whom either had a second reading which was lower than the cut-off value of $7.0 \mathrm{mmol} / / \mathrm{L}$ ( 3 women) or were delivered within an hour of two CBG levels being high (2 women), and therefore they did not need or get VRIII. NICE guidelines provide an excellent framework for managing patients with diabetes during delivery, but in some cases the decision to defer or avoid VRIII may be entirely appropriate, particularly if the delivery is imminent. After adopting the JBDS guidance we did not encounter any women who missed VRIII inappropriately.

Although our prescription chart now clarifies the need to start VRIII and monitor CBG every hour in all patients with preexisting type 1 diabetes, our woman with type 1 diabetes did not get adequate monitoring and this issue may need addressing in the educational sessions with midwives. Similar difficulties with monitoring have been noted in other studies. ${ }^{19}$ Our patient who was sent to theatre without a prior CBG highlights a safety breach and the ongoing need for education to the obstetric staff in hospitals. Unfortunately, the baby delivered to this woman was the only one who had mild neonatal hypoglycaemia.

In the current study all the women who received VRIII had CBG levels either within the target or had a satisfactory trend. Adjustment of the VRIII scale was therefore not needed. There was no incidence of maternal or neonatal hypoglycaemia in this group. This is in contrast to our previous study when only two women (22\%) on VRIII achieved the CBG target, two (22\%) had maternal hypoglycaemia and four (44\%) delivered babies with neonatal hypoglycaemia. Effective use of continuous glucose monitoring and continuous subcutaneous insulin infusion may 
be other options to control CBG levels in a tight target range without causing significant hypoglycaemia. However, this has not been studied in detail yet. ${ }^{20,21}$

\section{Neonatal hypoglycaemia}

Neonatal hypoglycaemia is not clearly defined in the literature, with values defining it from $1.6-2.2 \mathrm{mmol} / \mathrm{L}$ to $2.5-2.6$ $\mathrm{mmol} / \mathrm{L} .22 \mathrm{In}$ our group, hospital policy defined it as $<2.6 \mathrm{mmo} / \mathrm{L}$ at the time of the study. The most recent publication involving large numbers $(n=17,094)$ suggests that the normal glucose threshold could be $2.2 \mathrm{mmol} / \mathrm{L}$ for the 90th centile and 1.9 $\mathrm{mmol} / \mathrm{L}$ for the 95 th centile in the neonate. ${ }^{23}$ Routine measurement of neonatal blood glucose shows that $5 \%$ of apparently normal neonates have CBG levels $<1.7 \mathrm{mmol} / \mathrm{L}$ in the first few hours of life. ${ }^{24}$ Many experts, however, feel that symptomatic hypoglycaemia and a measured glucose of $<2.5 \mathrm{mmol} / \mathrm{L}$ should be managed aggressively. ${ }^{25}$ Others have recommended intravenous glucose for infants with glucose $<1.4 \mathrm{mmol} / \mathrm{L}{ }^{26}$

Of 24 studies reviewed recently, 19 specifically looked for a relationship between maternal glucose during labour and neonatal hypoglycaemia. In 10 of these studies there was an inverse relationship, with a similar trend in another three and six found no relationship. ${ }^{27}$ The authors believe that a target CBG of 4-6 mmol/L can be used safely and results in a low rate of neonatal hypoglycaemia. ${ }^{27}$ Some other authors did find an association with neonatal hypoglycaemia, but only at a threshold of maternal CBG >8 mmol/L. Interestingly, there was no increase in neonatal hypoglycaemia when CBG levels were kept below 8 $\mathrm{mmol} / \mathrm{L} .{ }^{11}$

In our study only one baby (1.7\%) had neonatal hypoglycaemia compared with $24(47 \%)$ in our previous study and another study. 17,28 Women with gestational diabetes comprised the largest and most comparable group in both studeis but, even in that group, 18 women (35\%) delivered babies with neonatal hypoglycaemia in the previous study. There was no neonatal hypoglycaemia to any women with known CBG levels in our study. A similar rate of overall neonatal hypoglycaemia (near $0 \%$ ) has been described in some other studies. ${ }^{17}$ Neonatal hypoglycaemia rates reported in the literature range from $0 \%{ }^{21,29}$ to $69 \% .^{30} \mathrm{In}$ one study $43 \%$ of babies had neonatal hypoglycaemia even when the mothers were maintained in the target range. ${ }^{19}$ This may be because neonatal hypoglycaemia is caused not only by hyperinsulinaemia during labour but also during pregnancy, especially when the diabetes control is not tight. ${ }^{5}$ Indeed, the four women in our previous study who had neonatal hypoglycaemia in spite of VRIII exhibited indicators of poor control during pregnancy (macrosomia, polyhydramnios and high $\mathrm{HbA}_{1 \mathrm{c}}$ ). ${ }^{17}$ Moreover, neonatal hypoglycaemia is commonly associated with maternal diabetes, ${ }^{31}$ but can also be the results of other reasons like pituitary adrenal and other metabolic causes. ${ }^{32,33}$

\section{Maternal hypoglycaemia}

In our study we did not see any maternal hypoglycaemia in women who received VRIII. In several studies, maternal hypoglycaemia was a recognised complication when trying to keep CBG levels at 4.0-7.0 mmol/L.34-38 In our previous study, two women (22.2\%) who used VRIII developed hypoglycaemia with $C B G<4$ $\mathrm{mmol} / \mathrm{L}$ compared with none of those who did not require VRIII $(p<0.02)$. Maternal hypoglycaemia can be as high as $56 \%$ with tighter targets of 4.0-6.5 mmol/L. ${ }^{30}$ Some studies have reported a reduction in maternal hypoglycaemia from $40 \%$ to $22.2 \%$ when the target CBG is relaxed. ${ }^{39,40}$ This is similar to the minor maternal hypoglycaemia noted in our study which was promptly and easily treated. The low incidence of hypoglycaemia in the current study in spite of a tight target of $4-7 \mathrm{mmol} / \mathrm{L}$, even in women with VRIII, is reassuring and may be partly because of more monitoring and effective adjustment of glucose and insulin arms of infusion by the staff, but requires more resources.

An editorial in Anaesthesia warns against maternal hypoglycaemia in women on VRIII and suggests targeting CBG at 6.0$8.0 \mathrm{mmol} / \mathrm{L} .^{12}$ The debate on tighter versus relaxed CBG monitoring frequency as well as target continues. This has raised questions about the possible benefit or harm from national guidance. ${ }^{41-43}$ In our current study we found that the implementation of JBDS guidance was associated with safe maternal outcomes for women with diabetes delivering in our hospital, although $20 \%$ minor maternal hypoglycaemia is still a concern. Further research is, however, urgently needed to confirm whether relaxation in CBG targets and frequency is possible without any deleterious effect on the neonatal outcomes. The recent suggestion is that, if we adjust for all the other neonatal factors, intrapartum glucose is not significantly associated with neonatal hypoglycaemia in all types of diabetes and therefore a relaxed approach is worth investigating,,$^{13}$ and that antenatal diabetes control may be more important than intra-partum glucose control. ${ }^{44}$ In patients who are undergoing regional analgesia or anaesthesia, CBG monitoring every half an hour and a more relaxed target has been suggested as an option in the JBDS guidance. ${ }^{15}$

\section{Limitations}

There are some limitations of this study. The true number of women with diabetes who delivered in our hospital in this period is higher than the number we were able to obtain from our Euroking database. Most of the women had gestational diabetes, with only one woman with type 1 diabetes and two with type 2 diabetes. We might have missed some women with preexisting diabetes in both studies, but perhaps more in the current study. We have presented our findings from the previous study (Tables 1 and 2) as an observation only, and a direct comparison is not possible due to differences in the number of women with pre-existing diabetes as well as services received by them. The data on CBG were missing for a number of women in our study. The near absence of neonatal hypoglycaemia in our current study may partly reflect advancement in treatment, care, support and education available to mothers this time compared with our previous study and may not be attributable solely to the adoption of JBDS guidance. Indeed, more women were reviewed by the diabetes team on each working day of the week in the present study compared with the previous one (100\% vs $76 \%)$. 


\section{Key messages}

- National Institute of Health and Care Excellence (NICE) recommends hourly capillary blood glucose (CBG) monitoring in women with diabetes during established labour and birth and maintaining CBG levels between 4.0 and $7.0 \mathrm{mmol} / \mathrm{L}$

- We adopted the Joint British Diabetes Societies (JBDS) guidelines to achieve these recommendations

- Thirty-six women $(60 \%)$ received hourly CBG monitoring and $30(50 \%)$ achieved CBG levels in the NICE recommended target range

- Only five women (8.3\%) needed variable rate intravenous insulin infusion (VRIII)

- There was only one baby with neonatal hypoglycaemia (1.7\%)

- Poor monitoring was seen more often in women who delivered by elective caesarean section compared with other modes of delivery $(p<0.0013)$

- Systems, prompts and clear guidelines formed the basis of effective and safe achievement of NICE recommended target blood glucose during delivery and birth

Regular daily review by the diabetes team might have helped continuous on-site education of maternity staff in addition to troubleshooting and reinforcement of protocols more effectively.

\section{Summary and recommendations}

With the adoption of JBDS guidelines, $60 \%$ of women with diabetes in established labour received complete hourly CBG monitoring of whom $71 \%$ achieved the NICE recommended target levels. VRIII was used in only $8.3 \%$ of women and neonatal hypoglycaemia was seen in only $1.7 \%$ of babies. There was no maternal hypoglycaemia in women who needed VRIII.

Maintaining CBG levels in mothers at $4-7 \mathrm{mmol} / \mathrm{L}$ during labour continues to remain difficult. Repeating CBG monitoring when the first CBG reading is $>7 \mathrm{mmol} / \mathrm{L}$ and starting VRIII only if two consecutive readings are $>7 \mathrm{mmol} / \mathrm{L}$ helped us avoid excessive use of VRIII but, at the same time, this approach was able to maintain appropriate metabolic control which might have contributed to low levels of neonatal hypoglycaemia.

Additional education should be in place to achieve, document and record CBG monitoring appropriately, especially in women who undergo CS. One-to-one staffing and regular education of all the staff involved is crucial. More randomised studies are urgently needed to ascertain the exact targets for this group of patients.

\section{Conflict of interest None. Funding None.}

\section{References}

1. National Institute for Health and Clinical Excellence. Clinical practice guideline. Diabetes in pregnancy: management of diabetes and its complications from preconception to the postnatal period. February 2015. Available at http://www.nice.org.uk/guidance/ng3 (accessed 6 October 2020)

2. Wahabi HA, Fayed A, Esmaeil S, et al. Systematic review and meta-analysis of the effectiveness of pre-pregnancy care for women with diabetes for improving maternal and perinatal outcomes. Plos One 2020 Aug 18;15(8):e0237571. https://doi.org/10.1371/journal.pone.0237571

3. HAPO Study Cooperative Research Group. Hyperglycemia and adverse pregnancy outcomes. N Engl J Med 2008;358:1991-2002. https://doi.org/ 10.1056/NEJMoa0707943

4. Pedersen J. Weight and length at birth of infants of diabetic mothers. Acta Endocrinol 1954;16:330-42. https://doi.org/10.1530/acta.0.0160330

5. Desoye G, Nolan CJ. The fetal glucose steal: an underappreciated phenomenon in diabetic pregnancy. Diabetologia 2016;59:1089-94. https://doi.org/10.1007/s00125-016-3931-6

6. Molsted-Pedersen L. Aspects of carbohydrate metabolism in newborn infants of diabetic mothers. I. Intravenous glucose tolerance tests (a) distribution and means of $K$ values, and (b) correlation between $K$ value and birth weight. Acta Endocrinol 1972;69:174-88.

7. Voormolen DN, de Wit L, Van Rijn BB, et al. Neonatal hypoglycemia following diet-controlled and insulin-treated gestational diabetes mellitus. Diabetes Care 2018;41:1385-90. https://doi.org/10.2337/dc18-0048

8. Shah R, Harding J, Brown J, McKinlay C. Neonatal glycaemia and neurodevelopmental outcomes: a systematic review and meta-analysis. Neonatology 2019;115:116-26. https://doi.org/10.1159/000492859

9. Jovanovic $L$. Glucose and insulin requirements during labor and delivery: the case for normoglycemia in pregnancies complicated by diabetes. Endocr Pract 2004;10(Suppl 2):40-5. https://doi.org/10.4158/EP.10.S2.40

10. Flores-le Roux JA, Sagarra E, Benaiges D, et al. A prospective evaluation of neonatal hypoglycaemia in infants of women with gestational diabetes mellitus. Diabetes Res Clin Pract 2012;97:217-22. https://doi.org/10.1016/ j.diabres.2012.03.011

11. Taylor R, Lee C, Kyne-Grzebalski D, Marshall SM, Davison JM. Clinical outcomes of pregnancy in women with type 1 diabetes. Obstet Gynecol 2002;99:537-4. https://doi.org/10.1016/s0029-7844(01)01790-2

12. Modi A, Levy N, Hall GM. Controversies in the peripartum management of diabetes. Anaesthesia 2016;71:750-5. https://doi.org/10.1111/anae.13487

13. Yamamoto JM, Donovan LE, Mohammad K, Wood SL. Severe neonatal hypoglycaemia and intrapartum glycaemic control in pregnancies complicated by type 1, type 2 and gestational diabetes. Diabet Med 2020;37:138-46. https://doi.org/10.1111/dme.14137

14. Hamel MS, Kanno LM, Has P, et al. Intrapartum glucose management in women with gestational diabetes mellitus: a randomized controlled trial. Obstet Gynecol 2019;133:1171-7. https://doi.org/10.1097/AOG.0000000000003257

15. Dashora UK, Temple R, Murphy H, et al. Joint British Diabetes Societies Inpatient Care Group. Management of glycaemic control in pregnant women with diabetes on obstetric wards and delivery units. Available at http://www.diabetologists-abcd.org.uk/JBDS/JBDS_Pregnancy_201017.pdf (accessed 14 October 2020).

16. Dashora U, Murphy HR, Temple RC, et al. Joint British Diabetes Societies (JBDS) for Inpatient Care. Managing hyperglycaemia during antenatal steroid administration, labour and birth in pregnant women with diabetes. Diabet Med 2018;35:1005-10. https://doi.org/10.1111/dme.13674

17. Dashora U, Rafique S, Tharayil G, et al. The feasibility and impact of implementing NICE guidance on diabetes control during delivery. $\mathrm{Br} J$ Diabetes 2017;17:100-06. https://doi.org/10.15277/bjd.2017.137

18. National Institute for Health and Clinical Excellence. Clinical practice guideline. Safe midewifery staffing for maternity settings. February 2015. Available at https://www.nice.org.uk/guidance/ng4/resources/safe-midwifery-staffing-for-maternity-settings-51040125637 (accessed 20 November 2016).

19. Barrett HL, Morris J, McElduff A. Watchful waiting: a management protocol for maternal glycaemia in the peripartum period. Aust NZ J Obstet Gynaecol 2009;49:162-7. https://doi.org/10.1111/j.1479-828X.2009.00969.x

20. Fresa R, Visalli N, Di Blasi V, et al. Experiences of continuous subcutaneous insulin infusion in pregnant women with type 1 diabetes during delivery from four Italian centers: a retrospective observational study. Diabetes Tech- 
nol Ther 2013;15:328-34. https://doi.org/10.1089/dia.2012.0260

21. lafusco D, Stoppoloni F, Salvia G, et al. Use of real time continuous glucose monitoring and intravenous insulin in type 1 diabetic mothers to prevent respiratory distress and hypoglycaemia in infants. BMC Pregnancy Childbirth 2008;8:23. https://doi.org/10.1186/1471-2393-8-23

22. Koh TH, Eyre JA, Aynsley-Green A . Neonatal hypoglycaemia--the controversy regarding definition. Arch Dis Child 1988;63:1386-8. https://doi.org/ 10.1136/adc.63.11.1386

23. Metzger BE, Persson B, Lowe LP, et al. Hyperglycemia and adverse pregnancy outcome study: neonatal glycemia. Pediatrics 2010;126:e1545-52. https://doi.org/10.1542/peds.2009-2257

24. Cornblath $\mathrm{M}$, Reisner $\mathrm{SH}$. Blood glucose in the neonate and its clinical significance. N Engl J Med 1965;273:378-81. https://doi.org/10.1056/ nejm196508122730707

25. Inder T. How low can I go? The impact of hypoglycemia on the immature brain. Pediatrics 2008;122:440-1. https://doi.org/10.1542/peds.2008-1417

26. Cornblath M, Hawdon JM, Williams AF, et al. Controversies regarding definition of neonatal hypoglycemia: suggested operational thresholds. Pediatrics 2000;105:1141-5. https://doi.org/10.1542/peds.105.5.1141

27. Ryan EA, Al-Agha R. Glucose control during labor and delivery. Curr Diab Rep 2014;14:450. https://doi.org/10.1007/s11892-013-0450-4

28. Agrawal RK, Lui K, Gupta JM. Neonatal hypoglycaemia in infants of diabetic mothers. J Paediatr Child Health 2000;36:354-6. https://doi.org/10.1046/ j.1440-1754.2000.00512.x

29. West TE, Lowy $C$. Control of blood glucose during labour in diabetic women with combined glucose and low-dose insulin infusion. Br Med J 1977; 1:1252-4. https://doi.org/10.1136/bmj.1.6071.1252

30. Kline GA, Edwards A. Antepartum and intra-partum insulin management of type 1 and type 2 diabetic women: impact on clinically significant neonatal hypoglycemia. Diabetes Res Clin Pract 2007;77:223-30. https://doi.org/10.1016/j.diabres.2006.10.024

31. Van Haltren K, Malhotra A. Characteristics of infants admitted with hypoglycemia to a neonatal unit. J Pediatr Endocrinol Metab 2013;26:525-9. https://doi.org/10.1515/jpem-2013-0009

32. Henquin JC, Sempoux C, Marchandise J, et al. Congenital hyperinsulinism caused by hexokinase I expression or glucokinase-activating mutation in a subset of $\beta$-cells. Diabetes 2013;62:1689-96. https://doi.org/10.2337/db121414
33. Hussain K, Aynsley-Green A. Hyperinsulinaemic hypoglycaemia in preterm neonates. Arch Dis Child Fetal Neonatal Ed 2004;89:F65-7. https://doi.org/10.1136/fn.89.1.f65

34. Feldberg D, Dicker $D$, Samuel $N$, et al. Intrapartum management of insulin-dependent diabetes mellitus (IDDM) gestants. Acta Obstet Gynecol Scand 1988:67:333-8.

35. Achong N, Duncan EL, McIntyre HD, Callaway L. Peripartum management of glycaemia in women with type 1 diabetes. Diabetes Care 2014;37:36471. https://doi.org/10.2337/dc13-1348

36. Lean ME, Pearson DW, Sutherland HW. Insulin management during labour and delivery in mothers with diabetes. Diabet Med 1990;7:162-4. https://doi.org/10.1111/j.1464-5491.1990.tb01352.x

37. Balsells M, Corcoy R, Adelantado JM, et al. Gestational diabetes mellitus: metabolic control during labour. Diabetes Nutr Metab 2000;13:257-62.

38. Rosenberg VA, Eglinton GS, Rauch ER, Skupski DW. Intrapartum maternal glycemic control in women with insulin requiring diabetes: a randomized clinical trial of rotating fluids versus insulin drip. Am J Obstet Gynecol 2006;195:1095-9. https://doi.org/10.1016/j.ajog.2006.05.051

39. Njenga $E$, Lind T, Taylor R. Five year audit of peripartum blood glucose control in type 1 diabetic patients. Diabet Med 1992;9:567-70. https://doi.org/10.1111/j.1464-5491.1992.tb01840.x

40. Carron Brown S, Kyne-Grzebalski D, Mwangi B, Taylor R. Effect of management policy upon 120 type 1 diabetic pregnancies: policy decisions in practice. Diabet Med 1999;16:573-8. https://doi.org/10.1046/j.14645491.1999.00124.x

41. Levy N, Hall GM. National guidance contributes to the high incidence of inpatient hypoglycaemia. Diabet Med 2019;36:120-1. https://doi.org/ 10.1111/dme.13795

42. Yamamoto JM, Murphy HR. Inpatient hypoglycaemia; should we focus on the guidelines, the targets or our tools? Diabet Med 2019;36:122-3. https://doi.org/10.1111/dme.13814

43. Dashora U, George S, Sampson M, et al. National guidelines have contributed to safer care for inpatients with diabetes. Diabet Med 2019; 36:124-6. https://doi.org/10.1111/dme.13815

44. Yamamoto JM, Corcoy R, Donovan LE, et al, CONCEPTT Collaborative Group. Maternal glycaemic control and risk of neonatal hypoglycaemia in type 1 diabetes pregnancy: a secondary analysis of the CONCEPTT trial. Diabet Med 2019;36:1046-53. https://doi.org/10.1111/dme.13988 